\title{
COMPETIÇÕES DE CAPOEIRA: APONTAMENTOS PRELIMINARES SOBRE OS JOGOS REGIONAIS REALIZADOS PELA FECAESP E PE- LA ABADÁ-CAPOEIRA NO ESTADO DE SÃO PAULO
}

\author{
Lívia de Paula Machado Pasqua \\ Universidade Estadual de Campinas, Campinas, São Paulo, Brasil \\ Marco Antonio Coelho Bortoleto \\ Universidade Estadual de Campinas, Campinas, São Paulo, Brasil \\ Elizabeth Paoliello Machado de Souza \\ Universidade Estadual de Campinas, Campinas, São Paulo, Brasil
}

\begin{abstract}
Resumo
Este trabalho aborda a faceta esportiva da Capoeira, em particular os "Jogos Competitivos de Capoeira", promovidos pela Federação de Capoeira do Estado de São Paulo e pela Associação Brasileira de Apoio e Desenvolvimento da Arte-Capoeira, em nível regional. Optamos por analisar os eventos organizados pelas referidas instituições por possuírem regulamento próprio e calendário regular de competições. Esta análise inicia-se por meio de uma revisão da literatura e complementa-se a partir de um estudo de campo que incluiu entrevistas aos mestres dessas instituições e o registro em diário de campo de uma competição promovida por cada uma delas. Os resultados revelam as principais características da estrutura competitiva desses campeonatos, bem como algumas diferenças, no que tange à divulgação dos resultados, organização das categorias e chaves, premiação, entre outros.
\end{abstract}

Palavras-chave: Capoeira; Competições; Educação Física.

\section{Introdução}

capoeira constitui-se numa manifestação corporal de identidade brasileira. Este
"jogo-dança-luta" modificou-se com o tempo, atualizando-se de acordo com a
dinâmica histórica de cada época. Assim sendo, a Capoeira, bem como as demais expressões culturais, apresenta uma multiplicidade de manifestações e interpretações (práticas e conceituais), conformando-se num fenômeno complexo cuja análise sempre será parcial e limitada. Partindo deste pressuposto entendemos como pertinente, a análise de alguns antecedentes históricos que norteiam as análises propostas nesta ocasião.

Durante a República Velha (1890-1930), a Capoeira foi considerada uma atividade delituosa. Seu reconhecimento como esporte nacional deu-se apenas na Era Vargas em 1941, quando o governo viu nesta atividade, enquanto esporte, uma ferramenta política poderosa, principalmente para a projeção internacional do Brasil. Tendo como meta, disciplinar amplamente o cenário esportivo brasileiro, o governo publica o Decreto-Lei $n^{\circ} .3 .199$, de 14 de abril de 1941, que segundo MENDES (1990) determina:

Cria-se, como órgão de alta superintendência, o CONSELHO NACIONAL DE DESPORTOS, com a atribuição de DIRIGIR, DISCIPLINAR e INCENTIVAR a prática dos desportos no País; institucionalizam-se 6 CONFEDERAÇÕES, uma de- 
las eclética, a CONFEDERAÇÃO BRASILEIRA DE DESPORTOS e as demais especializadas; permite-se a criação de FEDERAÇÕES e LIGAS e, obviamente, os CLUBES ou ASSOCIAÇÕES. Fica estabelecido que, nos ESTADOS FEDERADOS, a SUPERINTENDÊNCIA far-se-á através dos CONSELHOS REGIONAIS DE DESPORTOS, que em verdade sempre foram, meramente cartonais, face a ausência de poderes normativos. Enfim, edifica-se, com o DECRETO-LEI $\mathrm{N}^{\circ}$ 3.199/41, o que podemos chamar de SISTEMA DESPORTIVO NACIONAL [...] (GOMES, 1990, p. 35)

Como conseqüência deste decreto, a organização esportiva da Capoeira, uma vez que entendida como luta, como afirma Vieira (2004), "passou a integrar, também, desde sua fundação, a Confederação Brasileira de Pugilismo - CBP, por meio do Departamento Nacional de Luta Brasileira.” (VIEIRA, 2004, p. 2).

Alcança o status de patrimônio cultural brasileiro em 15 de julho de 2008, pelo IPHAN (Instituto do Patrimônio Histórico e Artístico Nacional), o qual também anunciou a inclusão do ofício dos mestres da capoeira no Livro dos Saberes, e da roda de capoeira no Livro das Formas de Expressão.

Devido ao seu sincretismo, a Capoeira se manifesta de diferentes formas que surgiram em suas atualizações em tempos e espaços diferentes, como as que acabamos de ver (Esporte e Arte). Logo, sua faceta esportiva segue a tendência apontada por PARLEBAS (2001), que discute a desportivização, ao afirmar este conceito como um "proceso social, especialmente institucional, y por extensión el resultado de dicho proceso, por el que uma actividad ludomotriz (casi juego, juego deportivo tradicional o casi deporte) alcanza la condición de deporte". (PARLEBAS, 2001, p. 131). Essa configuração esportiva é aqui entendida por competições entre capoeiristas de mesmo grupo ou intergrupos, podendo acontecer com abrangência regional, estadual, nacional e até internacional, como ocorre com outras modalidades esportivas já consolidadas, como é o caso do basquete, ginástica artística, futebol, entre outros.

O presente estudo teve por objetivo analisar e comparar as competições de Capoeira organizadas pela Federação de Capoeira do Estado de São Paulo (FECAESP), instituição subordinada à Confederação Brasileira de Capoeira - CBC e à Federação Internacional de Capoeira - FICA, e a Associação Brasileira de Apoio e Desenvolvimento da Arte-Capoeira (ABADÁ-Capoeira), particularmente nos eventos competitivos em âmbito regional. Optamos por analisar os eventos organizados por essas entidades por possuírem um calendário regular bem como regimento interno estabelecido, embora tenhamos constatado eventos promovidos por outras organizações de Capoeira.

Metodologicamente, realizamos uma revisão de literatura, e, posteriormente, um estudo de campo que incluiu entrevistas aos mestres de capoeira das referidas instituições, bem como o registro em diário de campo de uma competição promovida por cada uma das instituições anteriormente mencionadas.

Para a discussão dos dados, utilizamos a análise de conteúdo conforme Laurence Bardin (2008) "[...] um conjunto de técnicas de análise das comunicações que utiliza procedimentos sistemáticos e objectivos de descrição do conteúdo das mensagens" (BARDIN, 2008, p. 40). Organizamos os dados para uma pré-análise, posteriormente uma exploração do material e finalmente realizamos o tratamento dos resultados, a inferência e a interpretação. A principal técnica utilizada para o entendimento dos dados foi a análise categorial "Funciona por operações de desmembramentos do texto em unidades, em categorias segundo reagrupamentos analógicos. (BARDIN, 2008, p. 199). Discutiremos os critérios relacionados à estrutura da competição, às regras, às formas de pontuação e avaliação, ao corpo de jurados, à estrutura física e aos recursos humanos.

\section{A Capoeira Esportiva}


A capoeira compreendida como esporte, isto é, como atividade regrada, institucionalizada e competitiva, é apenas uma possibilidade de prática dessa arte brasileira, talvez uma das mais recentes, menos estudadas e mais contraditórias. Para compreendermos a capoeira esportiva, podemos partir do conceito da Capoeira Regional, a qual diz que a capoeira não deixa de ser "luta e combate", "manifestativa e contestativa", mas revela em si um caráter de esportividade, pois há o interesse de dominação de um corpo pelo outro. Assim José Milton Silva afirma:

Os regionais, os capoeiristas da linha mais modificada, são educados para competir e obter status. Desta forma, interpreta-se não muito como dança, mas a luta da Capoeira e, o próprio termo "luta" nos leva a figurar um corpo que procura espaço para dominar corpos, que, além de jogo, querem medir forças, distinguindo, é lógico, sua identificação a partir do outro, superando-o (SILVA, p. 69, 2003).

A Capoeira Regional surge com Mestre Bimba (Manoel dos Reis Machado), que em 1932 fundou a primeira academia oficial de Capoeira, o Centro de Cultura Física Regional da Bahia, por meio do Alvará $n^{\circ} 111$, da Secretaria da Educação, Saúde e Assistência de Salvador, transformando a Capoeira, assimilando golpes eficazes de outras lutas, desejando torná-la mais combativa, mais ágil, chamada de Luta Regional Bahiana, mais tarde denominada Capoeira Regional.

Com essa oficilização, Mestre Bimba obtém maior prestígio e aceitação social, passando a ensinar a capoeira com foco esportivo para as elites econômicas, políticas, militares e universitárias. O corpo na Capoeira, a partir disso, aparece mais "em pé". A Capoeira Regional Bahiana "surge mais direcionada ao domínio do próprio corpo, no sentido de proporcionar métodos e formas mais apuradas para o combate" (SILVA, p. 70, 2003). O capoeira ${ }^{1}$, deste período do Estado Novo (Brasil, 1937-1945), vive a realidade republicana, o capitalismo, diferente da realidade monárquica, deixa de ser mão de obra escrava e acaba por se tornar marginal e vadio. Os golpes devem ser mais rápidos, mais eficazes, assim como funcionam as relações de mercado, visando o lucro. A ideia de esporte também se relaciona ao capitalismo e influencia a arte da Capoeira.

Considerando todas essas relações, como pensar a competição da Capoeira? Como avaliar um corpo que se expressa, que improvisa, que luta, dança, joga e também compete? Como avaliar a dominação de corpos e o diálogo entre eles? A seguir comentaremos sobre o Primeiro Código Desportivo da Capoeira, a presença da Capoeira nos Jogos Escolares Brasileiros (JEB's) e uma breve apresentação das entidades que foram pesquisadas, FECAESP e ABADÁ-Capoeira.

\subsection{Primeiro Código Desportivo de Capoeira}

No Rio de Janeiro, em 1928, Annibal Burlamaqui, mais conhecido como Zuma, lança o livro intitulado "Gymnastica Nacional (Capoeiragem) Methodisada e Regrada", considerado o primeiro Código Desportivo da Capoeira. Nele estão inscritos como devem ser o campo de luta e as medidas dos raios de suas circunferências (raio círculo maior $4 \mathrm{~m}$ e raio círculo menor $50 \mathrm{~cm}$ ), a apresentação dos jogadores, os critérios de empate e desempate, o juiz, o campo (área, tipo de solo onde será demarcado o círculo da competição), as traves e as botinas (calçados que poderão ser usados nas competições), a nomenclatura dos golpes, e os exercícios para treinamento da capoeira.

\footnotetext{
${ }^{11} \mathrm{O}$ termo utilizado está baseado na obra de Inezil Penna Marinho, e significa indivíduo que pratica a Capoeira. 


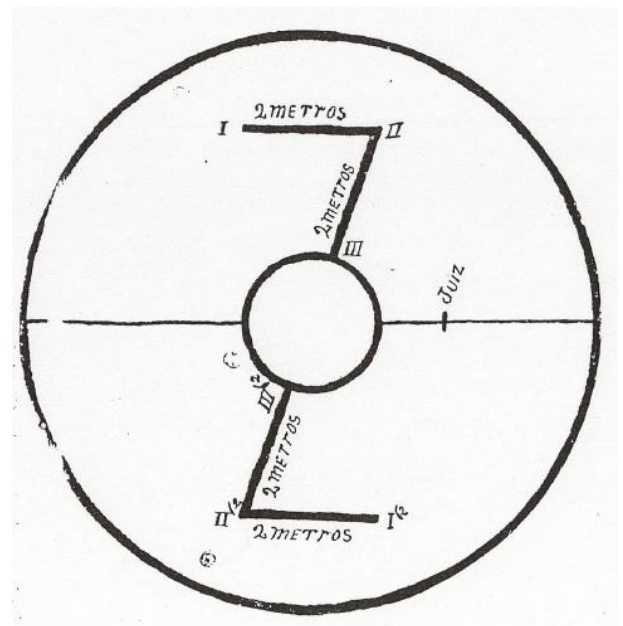

Figura 1. Campo de luta idealizado por Annibal Burlamaqui. Figura retirada de sua obra, Gymnastica Nacional (Capoeiragem) Methodisada e Regrada, Rio de Janeiro, 1928.

\subsection{A presença da Capoeira nos Jogos Escolares Brasileiros (Jeb’S)}

Os JEB's foram criados na década de 1960, fazendo parte do calendário esportivo do governo. Esse evento era voltado para o esporte de rendimento, para avaliar e melhorar a performance dos alunos, até que, em 1985, com a troca dos dirigentes dos JEB's, houve o intuito de valorizar o evento como acontecimento educacional e assim, a Capoeira entra em cena. Ao longo dos anos os JEB's passaram por várias transformações no âmbito de avaliações da competição de capoeira. Segundo BARBIERI et al (1995), a primeira tentativa de competição de capoeira foi organizada pela CBP (Confederação Brasileira de Pugilismo) em 1985. No ano seguinte, viu-se a necessidade de mudar o esquema da competição, "que atribuía pontos aos golpes e adotou-se a Roda de Capoeira, que é a forma original e natural de sua manifestação". Em 1987, os árbitros foram substituídos pelos Velhos Mestres, e deixou-se de valorizar apenas a performance atlética, passando a valorizar o esporte educacional. A competição foi reorganizada nos seguintes momentos: $1^{\circ}$ Momento: RODA - os alunos eram obrigados a jogar nos ritmos de São Bento Grande (da Capoeira Regional) e São Bento Pequeno (da Capoeira Angola); $2^{\circ}$ Momento: COREOGRAFIA - equipes demonstravam "mini-shows"; $3^{\circ}$ Momento: CONCURSO DE LADAINHA; $4^{\circ}$ Momento: SEMINÁRIO - cada equipe apresentava um trabalho; e $5^{\circ}$ Momento: CONFERÊNCIA COM OS MESTRES - que em 1989 passou a ser uma oficina prática com os mestres.

Os modelos de competição dos JEB’s até hoje são referências ou base para eventos internos de muitos grupos.

\subsection{Federação Internacional de Capoeira (FICA) ${ }^{2}$ e Federação de Capoeira do Estado de São Paulo (FECAESP)}

Annibal Burlamaqui foi um dos protagonistas da criação do Departamento de Luta Brasileira (Capoeiragem) da Federação Paulista de Pugilismo, em 1936. Com a Era Vargas, a Capoeira teve seu primeiro reconhecimento esportivo oficial, pois na constituição da Confederação Brasileira de Pugilismo já continha o Departamento Nacional de Luta Brasileira (Capoeiragem), que deu origem em 1992 à Confederção Brasileira de Capoeira (CBC). A CBC é

\footnotetext{
${ }^{2}$ Federação Internacional de Capoeira $-<\underline{\text { http://www.capoeira-fica.org }>}$
} 
entidade nacional de administração desportiva, criada em 23 de outubro de 1992, e é hoje a única a ser reconhecida pelo Comitê Olímpico Brasileiro - COB. Foi fundadora e está filiada à Federação Internacional de Capoeira (FICA), desde 1999.

A Confederação Brasileira de Capoeira (CBC) é vinculada ao Comitê Olímpico Brasileiro (COB), possuindo um Código de Competição que é regido pela FICA (Federação Internacional de Capoeira), órgão vinculado à CBC. Abrange 23 Federações Estaduais, 84 Ligas Regionais e Municipais, 1 Associação Brasileira de Árbitros, e cerca de 6.000 núcleos de ensino em todo o Brasil. Organiza competições nos níveis mundial, nacional, estadual e regional.

Devido ao presente trabalho tratar das competições no nível regional, devemos apresentar o órgão responsável pela Capoeira no Estado de São Paulo, a Federação de Capoeira do Estado de São Paulo - FECAESP. A coordenação das competições no nível regional que abrangem todo o Estado, em oito regiões, envolvendo cerca de 1.800 atletas em cerca de 3.600 disputas individuais, está a cargo do Mestre Valentim Rodolfo Mussarelli (Tim), presidente da FECAESP e vice-presidente técnico desportivo da FICA e do Mestre Edison Nascimento (Sarará), Presidente da Liga de Capoeira da Região Metropolitana de São Paulo.

A FECAESP é a única Federação credenciada pelo Governo do Estado de São Paulo a organizar esta competição (a competição dos Jogos Regionais do Estado de São Paulo), cujas regras são as definidas no Regulamento Desportivo Internacional de Capoeira.

\subsection{Associação Brasileira de Apoio e Desenvolvimento da Arte - Capoeira ABADÁ- Capoeira $^{3}$}

Dentre as competições não oficiais, ou seja, aquelas promovidas por associações ou grupos independentes, não credenciadas pelo governo, destacamos a ABADÁ-Capoeira, com sede no Rio de Janeiro desde 1989, com grande tradição na prática e desenvolvimento da Capoeira no Brasil e no mundo.

A ABADÁ-Capoeira (Associação Brasileira de Apoio e Desenvolvimento da Arte Capoeira), é uma entidade sem fins lucrativos, que tem como objetivo a difusão da cultura brasileira através da capoeira. Promove programas sociais que recuperam a noção de cidadania das pessoas. É um centro de pesquisa, que procura produzir conhecimentos sobre a arte, bem como busca centralizar todas as pesquisas já realizadas. Tem preocupação com o profissional de capoeira e sempre oferece aperfeiçoamento técnico aos professores vinculados ao núcleo que ensinam capoeira.

Atualmente, é um dos maiores grupos que divulga a cultura nacional, tanto no Brasil como no exterior, por meio da realização de projetos, seminários, palestras e cursos. Possui representação efetiva nos 26 estados brasileiros, no distrito federal, e também em 35 países, com cerca de 50 mil associados. Promove competições em todos os níveis: regionais, estaduais, brasileiros e mundiais, além dos Jogos Europeus de Capoeira.

\section{Metodologia}

Para se alcançar os objetivos definidos nesta pesquisa, foram realizadas entrevistas, num primeiro momento, com os mestres representantes dessas escolas, bem como o registro das competições nos Jogos Regionais em São Roque - SP, em julho de 2007, e na $8^{\text {a }}$. Edição dos Jogos Paulistas ABADÁ-Capoeira, em Americana - SP, em junho de 2008.

A partir dos dados coletados e com base no referencial teórico pesquisado, foram organizados dois quadros que mostram o panorama geral referente às competições de Capoeira

\footnotetext{
${ }^{3}$ Associação Brasileira de Apoio e Desenvolvimento da Arte-Capoeira- < www.abadacapoeira.com.br $>$ 
no Brasil, a partir da visão dos grupos entrevistados e um terceiro quadro mais especificamente voltado para a comparação dos campeonatos.

\section{Análise dos dados}

Como afirmado anteriormente, utilizamos a análise de conteúdo de Bardin (2008) para a análise, interpretação e discussão dos dados. Acerca do panorama geral das competições de Capoeira da FECAESP e da ABADÁ-Capoeira, apresentamos o quadro 1 - Dados Gerais que revela os mestres entrevistados de cada grupo, os princípios que regem as competições e a organização de seus regulamentos.

O quadro 2 - Capoeira e Esporte - traz a visão dos mestres sobre a faceta esportiva da Capoeira. Também discute a possibilidade da Capoeira se tornar um esporte olímpico.

Finalmente realizamos um exercício comparativo, a título ilustrativo, entre as competições que pode ser vista no quadro 4 - Comparação das competições organizadas pela FICA e pela ABADÁ-Capoeira - que por sua vez foi sub-dividido em $4 \mathrm{a}, 4 \mathrm{~b}$ e $4 \mathrm{c}$, em que são comparados: o tempo da competição, os participantes, a divisão das categorias, a vestimenta utilizada, o princípio das competições, os ritmos jogados, os procedimentos do campeonato, a pontuação, os juízes, o que é avaliado nos jogos, o critério de desempate, a desclassificação e a premiação.

Quadro 1. Panorama Geral das Competições FICA e ABADÁ-Capoeira. Dados Gerais.

\begin{tabular}{|c|c|c|}
\hline Sigla & FECAESP e FICA & $\begin{array}{c}\text { ABADÁ } \\
\text { CAPOEIRA }\end{array}$ \\
\hline Instituição & $\begin{array}{l}\text { Federação Internacional de Capoeira } \\
\text { e Federação de Capoeira do Estado de } \\
\text { São Paulo }\end{array}$ & $\begin{array}{c}\text { Associação Brasileira de Apoio } \\
\text { e Desenvolvimento da Arte } \\
\text { Capoeira }\end{array}$ \\
\hline Entrevistados & Mestre Tim & Mestre Camisa \\
\hline Competições & $\begin{array}{c}\text { A) Jogos Regionais e Abertos) Campeo- } \\
\text { nato Paulista, Campeonato Brasileiro e } \\
\text { Campeonato Mundial }\end{array}$ & $\begin{array}{l}\text { Competições nos níveis: regio- } \\
\text { nal, estadual, nacional e interna- } \\
\text { cional. }\end{array}$ \\
\hline $\begin{array}{l}\text { Princípio das } \\
\text { Competições }\end{array}$ & $\begin{array}{c}\text { Um joga contra o outro. } \\
\text { Avaliação do Atleta } \\
\text { "Sempre tem alguém que mostra mais } \\
\text { combatividade e superioridade no jogo" }\end{array}$ & $\begin{array}{c}\text { Um Joga com o outro. } \\
\text { Avaliação do Jogo e do Atleta } \\
\text { "Meu companheiro deve estar } \\
\text { bem para que eu possa construir } \\
\text { um bom jogo com ele" }\end{array}$ \\
\hline Regulamento & $\begin{array}{l}\text { Regulamento } \\
\text { próprio }\end{array}$ & $\begin{array}{c}\begin{array}{c}\text { Regulamento } \\
\text { próprio }\end{array} \\
\end{array}$ \\
\hline
\end{tabular}


Quadro 2. Panorama Geral das Competições de Capoeira no Brasil. Capoeira e Esporte.

\begin{tabular}{|c|c|}
\hline Grupo & $\begin{array}{l}\text { Capoeira e Esporte } \\
\end{array}$ \\
\hline $\begin{array}{c}\text { FECAESP } \\
\text { e FICA }\end{array}$ & $\begin{array}{l}\text { A competição é saudável e ajuda na padronização técnica da modalidade; ela dura } \\
\text { somente um dia, o resto do ano o capoeirista está envolvido com a arte, o lado } \\
\text { histórico e a musicalidade. } \\
\text { Acredito que ela chegará aos Jogos Olímpicos. O Campeonato Brasileiro já é } \\
\text { vinculado ao COB". }\end{array}$ \\
\hline $\begin{array}{c}\text { ABADÁ } \\
\text { CAPOEIRA }\end{array}$ & $\begin{array}{l}\text { A Capoeira é uma arte: envolve luta, expressão corporal, música e ritmo. O es- } \\
\text { porte é só uma parte da capoeira. Enquadrá-la somente como um esporte é limitá- } \\
\text { la. } \\
\text { E uma ressalva: não é porque tem competição que é esporte. Competição de esco- } \\
\text { la de samba, Festivais de Música, por exemplo, são competições e não são espor- } \\
\text { te. Nossa competição quebra vários tabus: homem jogando com mulher, pesado } \\
\text { com leve, fraco com forte... o capoeirista não pensa só na parte esportiva, ele } \\
\text { deve conhecer a capoeira, cantar, tocar e jogar vários tipos de jogos". } \\
\text { O caminho da capoeira não é o dos Jogos Olímpicos, é preciso entender sua ri- } \\
\text { queza, sua história, sua razão de existência e não simplesmente enquadrá-la no } \\
\text { sistema para chegar às Olimpíadas. A Capoeira já possui muito mais praticantes } \\
\text { que vários esportes olímpicos". }\end{array}$ \\
\hline
\end{tabular}

Quadro 3a. Comparação das competições organizadas pela FICA e pela ABADÁ-Capoeira.

\begin{tabular}{|c|c|c|}
\hline Competições & $\begin{array}{c}\text { FECAESP } \\
\text { e FICA }\end{array}$ & $\begin{array}{c}\text { ABADÁ } \\
\text { CAPOEIRA }\end{array}$ \\
\hline $\begin{array}{l}\text { Tempo de } \\
\text { Competição }\end{array}$ & Nos campeonatos regionais - um dia & Nos campeonatos regionais - dois dias \\
\hline $\begin{array}{l}\text { Quem } \\
\text { participa }\end{array}$ & $\begin{array}{l}\text { Só podem participar das competições } \\
\text { oficiais pessoas que estejam devidamen- } \\
\text { te legalizadas e cadastradas nos órgãos } \\
\text { oficiais de administração esportiva, ou } \\
\text { seja, FICA, FECAESP e CBC (Confe- } \\
\text { deração Brasileira de Capoeira). } \\
\text { No caso dos Jogos Regionais e Abertos, } \\
\text { qualquer atleta pode participar represen- } \\
\text { tando o seu município. }\end{array}$ & $\begin{array}{l}\text { Qualquer capoeirista da ABADÁ-Capoeira } \\
\text { Jogos Regionais: de corda amarelo-laranja a verde- } \\
\text { roxa. } \\
\text { Jogos Paulistas: de corda laranja a corda marrom. } \\
\text { Jogos Brasileiros e Jogos Mundiais: de corda azul a } \\
\text { marrom-vermelha. }\end{array}$ \\
\hline $\begin{array}{l}\text { Divisão } \\
\text { por catego- } \\
\text { rias }\end{array}$ & $\begin{array}{l}\text { Jogos Regionais e Jogos Abertos: os } \\
\text { atletas devem ser de } 18 \text { a } 42 \text { anos, e são } \\
\text { divididos nas categorias: feminino e } \\
\text { masculino e por peso: peso leve, peso } \\
\text { médio, peso meio pesado e peso pesado. } \\
\text { Jogos da FICA: idem, mas, além disso, } \\
\text { há a categoria por idades. }\end{array}$ & $\begin{array}{l}\text { Divisão por graduação, a exemplo, categoria azul e } \\
\text { azul-verde: competem entre si os capoeiristas de } \\
\text { corda azul e de corda azul-verde. } \\
\text { Não há divisão por sexo. } \\
\text { Não há divisão por peso. } \\
\text { Não há divisão por idade. } \\
\text { (Somente nos Jogos Brasileiros e Mundiais é que } \\
\text { existe uma categoria máster) }\end{array}$ \\
\hline Vestimenta & $\begin{array}{l}\text { Abadá branco (Calça de elanca branca), } \\
\text { sem símbolos, camiseta branca de gola } \\
\text { careca, com o símbolo da entidade (gru- } \\
\text { po de capoeira) no peito; ou da cidade, } \\
\text { no caso de Jogos Regionais e Jogos } \\
\text { Abertos. }\end{array}$ & $\begin{array}{l}\text { Abadá branco (Calça de elanca branca), com o sím- } \\
\text { bolo da ABADÁ-Capoeira, com o nome de seu } \\
\text { professor/instrutor/mestrando/mestre, camiseta do } \\
\text { evento e corda. }\end{array}$ \\
\hline
\end{tabular}


Quadro 3 b. Comparação das competições organizadas pela FICA e pela ABADÁ-Capoeira.

\begin{tabular}{|c|c|c|}
\hline Competições & $\begin{array}{l}\text { FECAESP } \\
\text { e FICA }\end{array}$ & $\begin{array}{c}\text { ABADÁ } \\
\text { CAPOEIRA }\end{array}$ \\
\hline $\begin{array}{l}\text { Princípio } \\
\text { das Competi- } \\
\text { ções }\end{array}$ & $\begin{array}{l}\text { Um joga contra o outro } \\
\text { Avaliação do atleta } \\
\text { "Sempre tem alguém que mostra mais } \\
\text { combatividade e superioridade no } \\
\text { jogo" }\end{array}$ & $\begin{array}{l}\text { Um Joga com o outro } \\
\text { Avaliação do Jogo e do Atleta } \\
\text { "Meu companheiro deve estar bem para que eu possa } \\
\text { construir um bom jogo com ele" }\end{array}$ \\
\hline $\begin{array}{l}\text { Ritmos } \\
\text { da Competi- } \\
\text { ção }\end{array}$ & Angola e Regional & $\begin{array}{l}\text { Benguela, Angola (de corda azul em diante), e Ben- } \\
\text { guela, Angola, São Bento Grande e Iúna (de corda } \\
\text { azul em diante). }\end{array}$ \\
\hline Procedimento & $\begin{array}{l}\text { São duas "voltas" (jogos) de dois } \\
\text { minutos de Angola e de Regional, } \\
\text { jogadas com pessoas diferentes, que } \\
\text { podem se escolhidas pelo próprio } \\
\text { jogador na "boca" da roda. }\end{array}$ & $\begin{array}{l}\text { Até corda laranja-azul: são realizados dois jogos de } \\
\text { São Bento Grande e Benguela na semifinal e mais } \\
\text { dois na final. } \\
\text { De azul pra cima: são Jogados dois Jogos de São } \\
\text { Bento Grande e Benguela e também Angola e Iúna. } \\
\text { Na semifinal e na final. }\end{array}$ \\
\hline Pontuação & $\begin{array}{l}1 \text { a } 10 \text { para cada jogador. Somam-se } \\
\text { os pontos a cada jogo. }\end{array}$ & $\begin{array}{l}1 \text { a } 10 \text { para o jogo. } \\
\text { Ao final, os pontos são iguais para os dois jogadores. } \\
\text { A partir dessa "nota" do jogo são descontadas as notas } \\
\text { individuais. }\end{array}$ \\
\hline Juízes & $\begin{array}{l}\text { Corpo de arbitragem composto de } 25 \\
\text { árbitros, sendo } 8 \text { árbitros laterais (que } \\
\text { dão a nota), } 4 \text { árbitros centrais, } 7 \\
\text { ritmistas e } 4 \text { mesários. } \\
\text { São feitas } 4 \text { rodas masculinas e depois } \\
4 \text { rodas femininas. }\end{array}$ & $\begin{array}{l}\text { São mestres e mestrandos da ABADÁ-Capoeira, ou } \\
\text { professores, nunca alguém de menor graduação fará a } \\
\text { avaliação. } \\
\text { É feita somente uma roda, onde participam todas as } \\
\text { graduações, cada uma em seu momento. }\end{array}$ \\
\hline
\end{tabular}


Quadro 3 c. Comparação das competições organizadas pela FICA e pela ABADÁ-Capoeira.

\begin{tabular}{|c|c|c|}
\hline Competições & $\begin{array}{c}\text { FECAESP } \\
\text { e FICA }\end{array}$ & $\begin{array}{c}\text { ABADÁ } \\
\text { CAPOEIRA }\end{array}$ \\
\hline $\begin{array}{l}\text { O que os } \\
\text { jogos avaliam }\end{array}$ & $\begin{array}{l}\text { Técnica, tradição, volume de jogo, } \\
\text { harmonia, combatividade e superio- } \\
\text { ridade. }\end{array}$ & Técnica, característica do jogo, objetividade e ritmo. \\
\hline Desempate & $\begin{array}{l}\text { "Soma das duas maiores notas, ou } \\
\text { pelas notas mais baixas, sorteio ou } \\
\text { até mesmo os dois no pódio" }\end{array}$ & $\begin{array}{l}\text { O capoeirista deve tocar o berimbau e cantar uma } \\
\text { música. Ás vezes é necessário, além disso, mais um } \\
\text { jogo de capoeira. }\end{array}$ \\
\hline Desclassificação & $\begin{array}{l}\text { "É desclassificado quem ferir a } \\
\text { integridade física e moral do com- } \\
\text { panheiro e realizar movimentos não } \\
\text { pertinentes aos estilos de jogo des- } \\
\text { critos no Regulamento da FICA". }\end{array}$ & $\begin{array}{l}\text { "Desclassificado quem ferir a integridade física e } \\
\text { moral do companheiro, mas é difícil isso acontecer, } \\
\text { pois é preciso do outro para jogar". }\end{array}$ \\
\hline Premiação & $\begin{array}{l}\text { Medalhas e Troféus até o terceiro } \\
\text { lugar, para cada atleta de cada cate- } \\
\text { goria e também no caso dos Jogos } \\
\text { Regionais, classificação dos Muni- } \\
\text { cípios. }\end{array}$ & $\begin{array}{l}\text { Troféus de } 1^{\circ} \text { a } 4^{\circ} \text { lugar geral de cada categoria, me- } \\
\text { dalha para o melhor de cada graduação dentro de sua } \\
\text { categoria, exemplo: categoria azul e azul-verde, me- } \\
\text { dalha para o melhor corda azul, medalha para o me- } \\
\text { lhor corda verde. } \\
\text { Medalhas também: para melhor jogo de Benguela, } \\
\text { melhor jogo de Angola, melhor jogo de Iúna, melhor } \\
\text { jogo de São Bento Grande e destaque feminino. } \\
\text { "O destaque feminino não privilegia nem inferioriza } \\
\text { as mulheres. Por enquanto, elas são a minoria dentro } \\
\text { das competições: competem dentro da categoria, den- } \\
\text { tro de sua graduação e entre elas mesmas. Elas aca- } \\
\text { bam tendo mais trabalho". }\end{array}$ \\
\hline
\end{tabular}

\section{Discussão dos dados}

\subsection{Tempo de competição}

Na ABADÁ-Capoeira a realização das competições se dá em dois dias, sendo que no primeiro dia há a chamada "peneira" entre os participantes, no qual são formadas de duas a três rodas com todos os capoeiristas de mesma graduação em cada uma delas. Nessas rodas, os capoeiristas jogam livremente e são escolhidos para fazer parte das chaves. As chaves ficam prontas para o dia seguinte e são formadas por sorteio.

Nos Jogos Regionais do Estado de São Paulo, a FECAESP realiza a competição num só dia. As categorias já estão pré-estabelecidas por peso e sexo, não há necessidade de realizar a "peneira", cada cidade pode possuir apenas um representante em cada categoria.

Podemos observar que na ABADÁ-Capoeira os participantes possuem uma desvantagem em se classificar para as chaves, pois a "peneira", não garante a participação na competição. Somente os que passaram por ela é que terão o direito de jogar os diferentes ritmos ao ser sorteado com alguém. Além disso, o critério de escolha não é claro, não há pontos na "peneira", apenas escolhas. Com a FECAESP, a vaga de todos na competição está garantida, porém, o número de capoeiristas é limitado pelo número de cidades.

\subsection{Competidores - Divisão por categorias}

Nos Jogos Regionais (FECAESP), cada cidade pode ter um representante nas diferentes categorias, feminino e masculino, peso leve, médio, meio-pesado e pesado. Atentando-se 
ao fato de que nesse campeonato o capoeirista perde a identificação por grupo, torna-se um representante de seu município, permitindo o encontro de praticantes de diferentes escolas de capoeira, sob um único regulamento (da FICA). As competições regionais da ABADÁCapoeira são internas, podendo apenas participar os capoeiristas desta escola. As categorias são dividas por graduação, ou seja, por nível técnico de cada capoeirista, não importando se é homem ou mulher, se possui 18 ou 30 anos. Com a FECAESP, capoeiristas de mesmo peso e mesmo sexo podem ter níveis de desenvolvimento diferentes, por pertencerem aos diversos grupos.

\subsection{Regras gerais, juízes e processo de avaliação}

Na FECAESP, entende-se a competição como "o jogar contra o outro", a avaliação é de um atleta em relação ao outro, ganha aquele que demonstrar maior superioridade e combatividade. Os pontos vão sendo acumulados individualmente, e o jogador sabe seus pontos imediatamente após o término do jogo, quando os juízes apontam suas placas com os números. O corpo de arbitragem é composto de 25 árbitros, sendo 8 árbitros laterais, 4 árbitros centrais, 7 ritmistas e 4 mesários. São avaliados: técnica, tradição, volume de jogo, harmonia, combatividade e superioridade.

Na ABADÁ-Capoeira, o princípio é "o jogar com o outro", a avaliação é do jogo e depois dos atletas, ou seja, os pontos vão para o jogo e posteriormente cada um leva essa pontuação para somar aos pontos do próximo jogo a ser realizado. Se necessário são realizados alguns descontos dessa nota por alguma falha individual do jogador. Não há clareza em relação à pontuação, pois os jogadores não sabem seus pontos até o final da competição. Os juízes são professores, mestrandos ou mestres da ABADÁ-Capoeira. São avaliados: técnica, característica do jogo, objetividade e ritmo.

\subsection{Ritmos da Competição}

Na FECAESP são formadas quatro rodas masculinas e quatro rodas femininas, respectivamente para cada categoria de peso. O participante realiza duas "voltas" (jogos) de dois minutos de Angola e de Regional, jogadas com pessoas diferentes, que podem ser escolhidas pelo próprio jogador na "boca" da roda.

Na ABADÁ-Capoeira é formada apenas uma roda por vez de cada categoria, a saber, corda amarela e amarelo-laranja; corda laranja e laranja-azul; corda azul e azul-verde; corda verde e verde-roxa. Os jogadores são sorteados para jogar com o outro, não se pode escolher. Até a categoria azul e azul-verde, cada participante realiza dois jogos de São Bento Grande e Benguela na Semifinal e na Final. Da categoria azul e azul-verde em diante, são realizados dois jogos de São Bento Grande e Benguela na Semifinal e na Final, intercalados com jogos de Iúna e Angola. Destacamos aqui a presença de dois ritmos diferentes, a Iúna e a Angola que não são competidos pela FECAESP.

\subsection{Análise comparativa das competições}

A partir das observações feitas nos Campeonatos e dos dados colhidos nas entrevistas, pudemos perceber as diferenças e as semelhanças entre os grupos. A FECAESP e a ABADÁCapoeira são semelhantes na organização: possuem regulamento e calendário de competições regulares. Entretanto, pudemos perceber alguns aspectos que as diferenciam.

A competição realizada pela FECAESP, nos Jogos Regionais do Estado de São Paulo, possui critérios de pontuação muito claros, em que tanto participantes como público conseguem entender e acompanhar a competição. São disputados apenas dois estilos de Capoeira, a 
Angola e a Regional. Muitas vezes, o capoeirista deve se adaptar ao regulamento da FICA, pois pode não ser de nenhum grupo federado à CBC (Confederação Brasileira de Capoeira), estando lá para representar o seu município, não importando a sua graduação. A competição é respaldada por um ritmo pensado para as quatro rodas que acontecem simultaneamente.

Na ABADÁ-Capoeira, os critérios de pontuação não são tão claros, não há placas informativas com os números dos pontos. São competidos mais de dois estilos, a saber, Benguela, São Bento Grande, Angola e Iúna. O capoeirista não precisa se adaptar ao regulamento, pois sendo uma disputa interna, ele já conhece as regras do seu grupo. A graduação é fundamental para se situar na competição, pois é ela que define sua categoria, não interessando a que cidade pertença. A competição parece mais próxima à realidade da capoeira, pois existe uma só roda em que todos assistem aos jogos dos outros, como se estivesse numa roda esperando sua vez para jogar, e, além disso, fazem parte do momento de competição do companheiro, pois quem não está competindo, está cantando e batendo palmas ou está tocando algum instrumento.

\title{
6. Considerações finais
}

A Capoeira esportivizada, muitas vezes obedece à lógica esportiva de seleção, especialização e instrumentalização, lembrando que o termo esporte significa "uma atividade corporal de movimento com caráter competitivo" (BRACHT, 2005, p.13). O esporte é resultado de um processo de modificação de jogos populares das classes mais baixas da Inglaterra, que sofreram a influência do processo de industrialização, no início no século XVIII. Os jogos populares eram inicialmente realizados com o sentido de festividade, sentido que estava fora deste novo âmbito industrial e urbano. $\mathrm{O}$ esporte, influenciado pela sociedade capitalista industrial, assume características básicas, definidas por Bracht (2005, p.14): "competição, rendimento físico, técnico, record, racionalização e cientifização do treinamento". O autor afirma a necessidade de o conceito ser explicado de acordo com seus diferentes objetivos e cria um esquema dual: a) esporte de alto rendimento ou espetáculo; b) esporte enquanto atividade de lazer. Na atualidade, a tendência mais marcante é a valorização do esporte de alto rendimento ou espetáculo, a "transformação do esporte em mercadoria veiculada pelos meios de comunicação de massa" (BRACHT, 2005, p.17). Com a esportivização da Capoeira, a prática tende a perder suas qualidades primordiais - a brincadeira, o jogo, o ritual, o teatral - cedendo lugar ao espetáculo, que é o precursor de sua venda como mercadoria, produto nacional, quase como "marca registrada".

Com este trabalho não buscamos dizer qual é a melhor competição, mas sim trazer à tona duas formas de se competir dentro da modalidade Capoeira. A partir disso, é possível corrigir possíveis falhas internas de cada instituição, assim como a geração de novas formas de se disputar essa arte que também é esporte.

Capoeira competitions: preliminary notes about the Regional Games conducted by FECAESP and ABADÁ-Capoeira in São Paulo

\begin{abstract}
Among the several aspects that make up the practice of Capoeira, this paper addresses its sporty side, in other words, the "competitive Capoeira games", made between members of the same group or between groups, at the regional, state, Brazilian or world levels. More specifically, this study aimed to compare the Capoeira competitions conducted by FECAESP (Capoeira Federation of São Paulo - which is subject to the Brazilian Capoeira Confederation -CBC and the International Federation of Capoeira - FICA) and Abadá-Capoeira (Brazilian Association for Support and Development of the Art - Capoeira), only at the regional level. These institutions were chosen because they have a regular schedule of competitions and rules of procedure for the championships. Methodologically we start from a literature review, later to perform a field study that included interviews with
\end{abstract}


Capoeira masters of those institutions as well as journaling field of a competition promoted by each of these institutions. Among the issues discussed, highlight: the competitive structure, rules, scoring system and evaluation, the jury, the physical infrastructure, human resources and other aspects. We found differences in the way of implementation and evaluation contests that deserve to be discussed here. Finally we believe that such information could contribute to further studies and understanding about this new facet of the sport Capoeira.

Keywords: Capoeira; Competitions; Physical Education

Competiciones de Capoeira: notas preliminares acerca de los Juegos Regionales realizados por FECAESP y ABADÁ-Capoeira en São Paulo - Brasil.

\section{Resumen}

Entre los varios aspectos que componen la práctica de la capoeira, este trabajo aborda su faceta deportiva, es decir, los "juegos competitivos de capoeira", realizados entre capoeristas en un mismo grupo o entre grupos diferentes, a nivel regional, estadual, brasileño o mundial. Más específicamente, este trabajo tiene como objetivo la comparación de las competiciones de capoeira realizadas por la FECAESP ( Federación de Capoeira del Estado de São Paulo - que está subordinada a la Confederación Brasileña de Capoeira - CBC y la Federación Internacional de Capoeira - FICA) y ABADÁ-Capoeira (Asociación Brasileña de Apoyo y Desarrollo del ArteCapoeira), apenas a nivel regional. Estas instituciones fueron escogidas por poseer un calendario regular y un reglamento interno para los campeonatos. Metodológicamente partimos de una revisión bibliográfica, para posteriormente realizar un estudio de campo que incluye entrevistas a los "mestres" de capoeira de las respectivas instituciones, así como el registro en diario de campo de una competición promovida por cada una de estas instituciones. Entre los aspectos analizados destacamos: la estructura competitiva, las reglas, el sistema de puntuación y evaluación, el cuerpo de jueces, la estructura física, los recursos humanos, entre otros. Encontramos diferencias en la forma de concretizarse y evaluar las competiciones que merecen ser aquí discutidas. Finalmente creemos que estas informaciones podrán contribuir para nuevos estudios y entendimientos sobre la reciente vertiente deportiva de la Capoeira.

Palabras-Clave: Capoeira; Competiciones; Educación Física

\section{Referências}

ABADÁ-CAPOEIRA, Associação Brasileira de Apoio e Desenvolvimento da Arte-capoeira. Disponível em: <www.abadacapoeira.com.br>. Acesso em: 19 out. 2010.

ARAÚJO, Paulo Coêlho de. Abordagens Sócio-Antropológicas da Luta/Jogo da Capoeira. Maia - Portugal: PUBLISMAI - Departamento de Publicações do Instituto Superior da Maia, 1997.

BARBIERI, César Augustus S. et al. A Capoeira nos JEB's. Brasília: DEFER, Centro de Informação e Documentação sobre a Capoeira (CIDOCA/DF), 1995. 100 p.

BARDIN, Laurence. Análise de Conteúdo. Lisboa: Ed 70, 2008. 281p.

BRACHT, Valter. Sociologia do esporte: uma introdução. (3. ed.). Porto Alegre: Unijui, 2005.

BURLAMAQUI, Annibal. Gynastica Nacional (Capoeiragem): methodizada e regrada. Rio de Janeiro: [s.n.], 1928.

CARDOSO, Carlos Luiz; TURELLI, Fabiana Cristina; GALVÃO, Thiago Botelho. Artes Marciais, o processo de ocidentalização do esporte e o desvio da dimensão do prazer. In: SILVA, Ana Márcia; DAMIANI, Iara Regina (org). Práticas Corporais. Construindo outros saberes em Educação Física. Florianópolis, Nauemblu Ciência \& Arte, 2006.

DAOLIO, Jocimar. Da cultura do corpo. Campinas, SP: Papirus, 1995. 
FALCÃO, José Luiz Cirqueia; SILVA, Bruno Emmanuel Santana da; ACORDI, Leandro de Oliveira. Gingando com o conceito de práxis no projeto capoeira e os passos da vida. In: SILVA, Ana Márcia; DAMIANI, Iara Regina (org). Práticas Corporais. Construindo outros saberes em Educação Física. Florianópolis, Nauemblu Ciência \& Arte, 2006.

FEDERAÇÃO INTERNACIONAL DE CAPOEIRA. Disponível em: <www.capoeirafica.org>. Acesso em: 07 set. 2010.

INSTITUTO DO PATRIMÔNIO HISTÓRICO E ARTÍSTICO NACIONAL. Disponível em: <www.iphan.gov.br>. Acesso em: 02 jul. 2010.

MARINHO, Inezil Penna. Subsídios para o estudo da metodologia do treinamento da capoeiragem. Rio de Janeiro: Imprensa Nacional, 1945.

MARINHO, Inezil Penna. Subsídios para a História da Capoeiragem no Brasil. Rio de Janeiro: Imprensa Nacional,1956.

MENDES, Renato Geraldo. A Reformulação do Esporte Brasileiro. Revista da Fundação de Esporte e Turismo 2. Curitiba-PR, n. 2 , p.34-37, 1990. Disponível em: <http://boletimef.org/biblioteca/2664/artigo/BoletimEF.org_A-reformulacao-do-esportebrasileiro.pdf>. Acesso em: 07 nov. 2010.

PARLEBAS, Pierre. Juegos, deporte y sociedad: léxico de praxiología motriz. Barcelona: Pai do tribo, 2001.

SILVA, José Milton Ferreira da. A linguagem do corpo na Capoeira. Rio de Janeiro: Sprint, 2003.

VIEIRA, Sergio Luiz de Souza (Brasil). Da Capoeira: como patrimônio cultural. 2004. Disponível em: <http://www.capoeira-fica.org/enlaces.html>. Acesso em: 01 nov. 2010.

Recebido em: 17-03-2011

Aprovado em: 27-01-2012

Endereço para correspondência:

liviapasqua@yahoo.com.br

Lívia de Paula Machado Pasqua

Unicamp

Cidade Universitária Zeferino Vaz

Barão Geraldo, Campinas - SP

13083-970 